\title{
Let's go back to tennis! Playing tennis safe for everyone's health
}

\author{
Diego García
}

\section{ABSTRACT}

This article, which is based on contributions from coaches and specialists, shares some proposals and suggestions that will allow the return to tennis activity in the best possible way. The information provided is structured into prior considerations, considerations before entering the court, development of tennis sessions and the end of the activity. We hope that these proposals will make it easier for coaches to return to the tennis court.
Key words: COVID-19, security, training, trainers.

Received: 10 April 2020

Accepted: 14 June 2020

Corresponding author: Diego

García, Argentina. Email:

diego17carlos@gmail.com

\section{INTRODUCTION}

The objective of this article is to collaborate of with the coaches, players and also with the authorities of the different institutions and organisations prior to the return to the tennis. This paper is based on the e-book Let's go back to tennis! (García et al., 2020), which includes contributions from several Argentine coaches and specialists who agreed to share ideas that may be used in the weeks prior to returning to tennis, as well as exercises for private sessions for the first months after the opening of the quarantine. We can all do better if we help each other in this return to tennis. As we write this article, there are several countries already authorised to play tennis. The main principle that underpins this idea is to propose a return to the activity in a safe, responsible and professional way, and that we do not have to turn back. We also share suggestions included in different international protocols and we recommend consulting the pages of the respective National Associations, the International Tennis Federation and the Ministries or Organizations of International Health and Sport in the different countries (International Tennis Federation, 2020; World Organization of Health, 2020).

\section{The information provided will be structured in four sections:}

1. Previous considerations, which include some tips for retaining former players, some promotional work to reach new players, and a possible agreement between the coach and the players based on the new relationships that will be established.

2. Considerations before going back to the court, where some actions are suggested that will make players aware of the care and security necessary on their way and while staying on the court.
3. Development of the sessions, where a proposal of classification and some examples of exercises for the first months of adaptation during the quarantine are shown.

4. The end of the activity, where some considerations are proposed to consider in order to look after our health and that of our players at the end of the session.

\section{PREVIOUS CONSIDERATIONS}

Tips for the retention of our former players

It is very likely that we have all been in contact with our players in this quarantine, but the time is coming to play again. So, it's time to go back with more energy, and to engage all our players to continue playing. These are some suggestions proposed by Echegaray (2020) in order to achieve this goal:

1. Submit a video with a "back to tennis" psycho / physical / tennis preparation session routine.

2. Send them the Back to Tennis Protocol approved by the Ministry of Health of your Nation.

3. Send motivational messages via WhatsApp.

4. Send the players the plan of the first session including the exercise routines.

5. Share videos from other places in the world that are already playing tennis.

6. Send the players a list of sports movies, it is best if they are tennis movies, in order to promote participation.

7. Send the players a flyer with the authorisation of the venue where the tennis programme is delivered.

8. Ask a player, a former player or a celebrity known to all, to send a personalised message to our players. 
9. Ask a player who started playing tennis to choose a "friend" and send him a video recommending taking tennis lessons.

10. Wait for the players with your cell phone, record them in those "previous steps" when entering the court. Then make a video with all the players that attended the practice during the week and send it to them.

11. We recommend to follow up and / or add to the sessions before or during their delivery, to an organisation theme group in "zoom".

\section{Promotion tips that will allow us to reach future players}

It is important to focus on the benefits of tennis to put in place an adequate promotion now (Crespo, 2020). In doing so, we will take advantage in relation to those sports that will be without activity at the start of the return to the activity. This can be done by sharing links to posts about the benefits of tennis as a safe, simple and achievable activity in these days. In addition, it is important to make yourself known on social networks, have a website, deliver sessions that everyone will be able to access, or offer free sessions to unconventional clients such as managers or administrators.

It is crucial to have a possible agreement between the player and the coach that contains all the points necessary for this new relationship.

Times have changed, the Covid-19 is still a threat. It is substantial to limit the obvious framework between what the player who is going to receive thinks and what we are going to deliver in this "new" tennis session. Therefore, it is relevant to have the necessary meetings with our players to explain them how we are going to deliver tennis sessions in these times of Covid-19. In order to do this, it is important to have a written summary of the protocol that will be followed in our sessions and that will have the health and care of all participants as the main goal. We have to send it to the players and parents for them to agree, by assuming their responsibility, with the conditions.

\section{CONSIDERATIONS BEFORE GOING ON COURT}

This section will share some important recommendations in order to ensure that our players are well prepared to participate in the tennis session which will ensure that they will continue hiring our services (and that they will continue taking sessions with good health).

\section{Preparation of the body for the first session (Cristian Elsesser)}

As preparation, a dynamic warm-up will be necessary before each session and more specifically, in the first session postquarantine. We will try to carry out a comprehensive neuromuscular activation which will bring the body and mind in tune with the tasks that are to be performed afterwards. The strategy will be to engage players in a short activity, at medium intensity, agile and dynamic; where in 7 to 10 minutes we will seek to include actions that will activate each body segment as follows:
- $\quad 3 / 4$ highly dynamic multi joint mobility exercises

- Mid zone activation exercises: Planks / lateral / spinal planks

- 1 upper body strength exercise (pole squats / lunges / bench climb)

- 1 upper body exercise

- 3 exercises of running technique over 8 to 10 meters

Management of anxiety to play again (Claudio Sosa)

This involuntary break has undoubtedly brought many anxiety disorders to the population. Therefore, our players and also, we as coaches, may feel a high dose of anxiety that should be managed in the best possible way (Young, 2014). We share the following suggestions that will help players and coaches alleviate that anxiety before the first session.

\section{For the players:}

- Before the session begins, take a minute, close your eyes, and imagine hitting the ball, then shadow the strokes just before you start hitting the ball with your coach.

- Be careful with the anxiety of willing to do everything perfect. It is crucial to have a goal related to what motivates you to play tennis.

- Exhale the air when hitting the ball will help you to play more relaxed, help the flow of your shot and avoid injuries.

- After each rally, focus on one or two deep breaths to oxygenate your brain and muscles.

- Work your positive self-talk. Reward yourself every time you hit the ball well.

\section{For coaches:}

- $\quad$ Prepare the sessions.

- Be careful with the anxiety of willing to transmit to your players lots of knowledge and all together.

- Plan a fun, agile session for the players to get active and enjoy.

\section{CARE WITH THE COVID-19 BEFORE STARTING THE FIRST SESSION}

The care that both players and coaches should have to avoid the spread of the Coronavirus is very important. Some general guidelines, which you can consider to add to the ones you may already implement as appropriate, are the following:

- By specifying the schedule of the session, the player and coach agree to express their good health.

- In case of symptoms, the appropriate protocols will be activated.

- It is recommended to keep a record of each player.

- If it is possible, consider removing the entrance doors to the courts or that they are only manipulated by the coach, after disinfecting them. 
- The coach and player will have each one a space reserved for their belongings and a disinfection kit on one side of the court and the player on the other side, which will be disinfected before, during and after the session, according to the established protocols of disinfection.

- $\quad$ Both the player and the coach will use face masks until the moment each one is located on each side of the court.

- The use of a cap and glasses is recommended.

- In the session, only the coach will be in charge of manipulating his own racket, the 6 available tennis balls and the 4 cones.

- We recommend that the coach puts 6 balls in small waste bags, one for each session of the day, in order to avoid that these are shared by players. In their free time, coaches should sanitise those balls already used (Fernando Bertolini).

- Both the player and the coach will try not to touch their faces with their hands during the session.

- Before the first session of return to the activity, we recommend sending to the players the tutorials created by different National Associations such as the USTA and the French Tennis Federation.

Class development

The general format proposed for the sessions is as follows:

- Private sessions (coach +1 player) with preventive social distancing.

- The coach can only have at his disposal: 6 balls and 4 cones, which only he can manipulate.

- The player can only hit the balls sent by the coach. Keeping the social distance imposed by the Covid19 , the player will be able, if necessary, to reach the balls only with the racket, without touching them with the hands.

Leo Alonso proposes a classification that will help organise the exercises according to the objectives of the coach:

1. Systematic: they are repetition exercises to mechanise the shot or movement technique. They are usually closed since the only objective is the conscious repetition of the "new" mechanics that only, when it is repeated enough times, will replace the previous habit.

2. Resolutive: those exercises in which a game situation should be solved. They involve reading the ball received and choosing the answer to that situation. The mental process that dominates these types of drills is tactical (the first thing you do is to "read" the ball that comes and then choose the appropriate response). It is ideal to conduct them using live ball drills.

3. Competitive: they are exercises in which the players play points with one objective: to win. Therefore, it is very important that the coach does not provide technical instructions but guides the player on how to be efficient, competitively speaking, in order to win.

The e-book We return to tennis! includes examples of more than 40 exercises.

The end of the activity

- It is important to consider the following recommendations at the end of the session to continue with the care of our health and that of the players:

- The final greeting will be made respecting the preventive social distancing.

- The payment of the sessions will be attempted by electronic means. In case of receiving physical money, it is recommended to sanitise it following the established protocols (i.e. spray it with $70 \%$ alcohol)

- We propose sessions to be scheduled with a 15 minutes break between them (i.e. If one session ends at 9, the other session begins at 9:15). This avoids contact between the player who leaves and the one who comes to the session, as well as allowing us to sanitise ourselves, sanitise the materials and plan the next session.

- Once the session is over, the coach should sanitise:

a. the area that corresponds to the coach

b. the area that corresponds to the player

c. the entrance gate to the court

d. the belt and the net posts

e. any element that is likely to spread the virus

It is essential that the coach finishes the activity of the day having sanitised all the balls, the cones and the clothes used. This action will prevent the circulation of the virus.

\section{CONCLUSIONS}

First of all, we are immensely grateful to each and every one of the colleagues who shared their knowledge, and collaborated with their exercises and time, in these moments of pandemic. These are times of immense change in our relationships with those we love, and our players are part of our lives and affections. From our resilience, imprint and adaptation, the best will come. Definitely!

\section{REFERENCES}

Crespo, A. (2020). La enseñanza del tenis como negocio: los entrenadores como creadores de valor añadido. ITF Coaching and Sports Science Review, 80 (28), 27-28.

García, D. (2020). E-book Volvemos al tenis.

International Tennis Federation. (2020). Pautas para el regreso al tenis. Recuperado de https://www.itftennis.com/media/3447/pautaspara-el-regreso-al-tenis-esp.pdf

Organización Mundial de la Salud (2020). Brote de enfermedad por coronavirus (COVID-19). https://www.who.int/es/emergencies/diseases/novelcoronavirus-2019 
Young, J.A. (2014). La resiliencia del entrenador ¿Qué significa, por qué es importante y cómo desarrollarla?. ITF Coaching and Sport Science Review, 63, 10-12.

RECOMMENDED ITF TENNIS ACADEMY CONTENT (CLICK BELOW)

\section{ITF Academy}

Copyright (c) 2020 Diego García

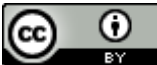

This text is under a Creative Commons BY 4.0 license

You are free to Share - copy and redistribute the material in any medium or format - and Adapt the content - remix, transform, and build upon the material for any purpose, even commercially under the following terms:

Attribution: You must give appropriate credit, provide a link to the license, and indicate if changes were made. You may do so in any reasonable manner, but not in any way that suggests the licensor endorses you or your use.

CCBY 4.0 license terms summary CCBY4.0license terms 